\title{
Perceptions of Childhood Relationships With Mother and Father: Daily Emotional and Stressor Experiences in Adulthood
}

\author{
Melanie H. Mallers \\ California State University, Fullerton \\ Shevaun D. Neupert \\ North Carolina State University
}

\author{
Susan T. Charles \\ University of California, Irvine \\ David M. Almeida \\ The Pennsylvania State University
}

\begin{abstract}
Adults who report having had high-quality relationships with their parents during childhood have better overall mental health and are at decreased risk for mental disorders compared with those who report low parental relationship quality. Researchers have predominantly focused on the relationship with the mother, oftentimes excluding the unique role that fathers may play in the long-term development of their offspring. The current study examined the unique associations of recalled childhood experiences of mother-child and father-child relationship quality with daily emotional experiences and stress processes in adulthood. Men and women $(N=912$, ages $25-74)$ retrospectively reported the quality of their childhood relationships with their mother and father. Later, they reported their daily psychological distress and stressor exposure every night over 8 consecutive evenings. Results indicate that motherchild relationship quality was related to lower levels of daily psychological distress. The quality of both mother-child and father-child relationships was related to stressor exposure, but only father-son relationship quality was related to lower levels of emotional reactivity to stressors during adulthood.
\end{abstract}

Keywords: mother-child, father-child, relationship quality, psychological distress, daily stressors

The quality of parenting one receives during childhood has lasting effects on health and well-being (e.g., Shaw, Krause, Chatters, Connell, \& Ingersoll-Dayton, 2004). Parent-child relationship quality is often assessed by asking respondents about childhood experiences, such as the level and quality of support, nurturance, and affection they received from their parents. These viewpoints are strong predictors of psychological and physical well-being throughout life (e.g., Antonucci, Akiyama, \& Takahashi, 2004; Repetti, Taylor, \& Seeman, 2002; Roberts \& Bengston, 1996; Russek \& Schwartz, 1997; Seeman \& Syme, 1987; Shumaker \& Czajkowski, 1994; Taylor, Lerner, Sage, Lehman, \& Seeman, 2004; Turner \& Muller, 2004; Umberson, 1992; Wickrama, Lorenz, \& Conger, 1997). Though the extent to which these perceptions vary across development and into adulthood is debated (Aquilino, 1997), research suggests that views of parent-child relationships remain relatively consistent from adolescence to adulthood (Rossi \& Rossi, 1990). Furthermore, these perceptions predict adulthood physical health better than other known corre-

This article was published Online First September 27, 2010.

Melanie H. Mallers, Department of Psychology, California State University, Fullerton; Susan T. Charles, Department of Psychology and Social Behavior, University of California, Irvine; Shevaun D. Neupert, Department of Psychology, North Carolina State University; David M. Almeida, Department of Human Development, The Pennsylvania State University.

Correspondence concerning this article should be addressed to Melanie H. Mallers, Department of Human Services, California State University, 800 North State College Boulevard, Fullerton, CA 92831. E-mail: mhornmallers@fullerton.edu lates, such as current age, familial history of illness, and lifestyle behaviors (Medalie \& Goldbourt, 1976; Russek \& Schwartz, 1996; Seeman \& Syme, 1987). For the present study, we examined adults' retrospective reports of the quality of their childhood relationships with their mother and father and link them with current emotional well-being (i.e., psychological distress), daily stressor exposure, and emotional reactivity to daily stressors.

Researchers have discussed the pathways leading from the receipt of poor parenting in childhood to worse mental health in later life. These models assert that children who receive chaotic, harsh, or neglectful care from their parents develop poor emotion regulation strategies, which in turn leaves them more susceptible to emotional distress later in life (e.g., Repetti et al., 2002). Research findings are consistent with these models, indicating that retrospective ratings of low parental quality during childhood are related to higher levels of negative emotionality in adulthood, including anger, hostility, depression, and anxiety (Lehman, Taylor, Kiefe, \& Seeman, 2009; Turner \& Muller, 2004). In addition, adults who report poorer relationship quality with their parents during childhood have both lower self-confidence and lower emotional well-being than their higher scoring counterparts (e.g., Diehl, Elnick, Bourbeau, \& Labouvie-Vief, 1998). These studies underscore the importance of parental relationship quality in childhood on later emotional well-being.

Current findings, however, often are limited by samples that are small, all male, or consist only of college students. In addition, studies often restrict their research to one-time assessments of emotional well-being. More recently, researchers have begun to focus on the importance of capturing dynamic emotional processes in daily life (e.g., Almeida, 2005). A growing number of studies 
have examined the temporal covariation of daily stressors and psychological distress to capture individual differences in emotional reactivity to stressors (Larsen, Billings, \& Cutler, 1996; Larsen \& Kasimatis, 1990; Tennen, Suls, \& Affleck, 1991). Furthermore, research has focused almost exclusively on the motherchild relationship (e.g., Biller, 1974; Levine, Murphy, \& Wilson, 1993; Saracho \& Spodek, 2008). When fathers are mentioned, their contribution to their children's welfare is often limited to financial support or to the effects of inadequate or absent fathering (A. J. Hawkins \& Dollahite, 1997; L. D. Marks \& Palkovitz, 2004). The present study uses a national data set of men and women spanning 5 decades of adulthood, from ages 25 to 74 years, to study the unique associations between emotional experience in adulthood and perceived quality of relationships with both the mother and the father in childhood. Specifically, we examined mother-child and father-child relationship quality with overall emotional experiences, including levels of daily distress and emotional reactivity to daily stressful events.

\section{Sociohistorical Influences on Mother-Child and Father-Child Relationships}

Parent-child interactions are personal and often private encounters, yet they are influenced by sociohistorical influences. Two such influences are socioeconomic status (SES) and the historical expectations and cultural mores about parenting (Coltrane, 2004; Doherty, Kouneski, \& Erickson, 1998). Parents living in poorer SES conditions, for example, tend to be less supportive and nurturing than financially secure parents (House, Landis, \& Umberson, 1988; Shaw, Krause, Chatters, Connell, \& Ingersoll-Dayton, 2003). In addition, historical differences in child-rearing practices and gender roles also shape what is considered good parenting in the United States, especially as it relates to culturally determined role expectations of fathers (Coltrane, 2004; Morman \& Floyd, 2002; Saracho \& Spodek, 2008). From the mid-19th century through the Great Depression, the father primarily fulfilled the role of breadwinner in which good fathers met their family obligation by earning the majority if not all of the family income (Lamb, 2004). Beginning in the 1930s and 1940s, fathers continued to be breadwinners, but their role was extended to that of a sex-role model, especially for their sons. Good fathers also exemplified masculine traditional traits. By the beginning of the 1970s, fathers were defined as good if they were the new nurturant father who actively participated in child care duties (Lamb, 2004; E. H. Pleck \& Pleck, 1997). The current study examined retrospective reports of both mother-child and father-child relationship quality among adults who ranged from ages 25 through 74 years and were children across 5 decades of the 20th century in the United States.

\section{Examining the Unique Roles of the Mother and the Father}

Research on parenting focuses predominantly on the primary caregiver, typically the mother. Researchers, however, are increasingly interested in the unique contributions of each parent on a child's short-term and long-term development. For example, mothers spend more time in routine caregiving activities with their children (Parke, 1996) and are most often the primary source of physical comfort and safety for the child (e.g., Baumrind, 1980;
Blankenhorn, 1995; Dempsey, 2000; Lamb, 1997; J. Pleck, 1997). Fathers, in contrast, more often engage the child in physical and stimulating interaction during play (Parke \& Tinsley, 1987). Research has shown that through these active play behaviors, including roughhousing, talking, and recreational activities (Jacklin, DiPietro, \& Maccoby, 1984; Lamb, 1997), children have the opportunity to develop emotion regulation and problem-solving skills (e.g., Biller, 1993; Labrell, 1996). In addition, men more than women often encourage children to take risks, while at the same time ensuring their safety and providing an environment where children learn to navigate through unfamiliar situations and to stand up for themselves (Paquette, 2004). Thus, mothers may play a stronger role for shaping overall safety and emotional health, and involved fathers may have stronger influence in shaping a child's sense of industry and competence for handling and adapting to new challenges (e.g., Amato, 1986; Biller \& Solomon, 1986; Clarke-Stewart, 1978; Radin, 1982), as well as managing emotions (Easterbrooks \& Goldberg, 1990) and adapting to stressful situations (Biller, 1993; Mischel, Shoda, \& Peake, 1988).

The quality of the father-child relationship may be especially significant for emotional regulation processes for sons, as compared with daughters. When fathers play an active role in the lives of their children, they generally behave differently with their sons, and they tend to spend more time with sons than with daughters (Lamb, 1987). Fathers also report being closer to their sons than to their daughters (Starrels, 1994). There is little indication, however, that mothers treat or prefer sons over daughters (Aldous, Mulligan, \& Bjarnason, 1998; Harris \& Morgan, 1991; Lamb, Ketterlinus, \& Fracasso, 1992; J. Pleck, 1997; Siegal, 1987).

\section{Daily Stressors and Emotional Experiences}

In the current study, we examined the relationships between mother-child and father-child relationship quality during childhood in relation to daily emotional experiences during adulthood. Until now, researchers have linked these childhood relationships to one-time assessments of emotion-related outcomes in adulthood. No study has examined how these early childhood relationships are related to stressor exposure or emotional reactivity to daily stressors. Daily stressors are the routine challenges of day-to-day living, such as interpersonal arguments, work deadlines, and traffic jams. Although relatively minor, they exert immediate negative effects on physical and psychological well-being on the day they occur (Almeida, 2005; Almeida, Wethington, \& Kessler, 2002; Bolger, DeLongis, Kessler, \& Schilling, 1989) and also accumulate over time to contribute to more serious emotional reactions (Almeida, 2005; Kanner, Coyne, Schaefer, \& Lazarus, 1981; Lazarus \& DeLongis, 1983; Lazarus \& Folkman, 1984; Pearlin, Lieberman, Menaghan, \& Mullan, 1981; Pearlin \& Schooler, 1978). Stressor exposure is the likelihood that an individual will experience a daily stressor (Bolger \& Zuckerman, 1995). Reactivity is the likelihood that an individual will react emotionally to daily stressors (Almeida, 2005; Bolger \& Zuckerman, 1995). At the daily level, emotional reactivity refers to the change in daily distress that ensues after a person experiences a stressful event. Thus, reactivity is an indirect measure of emotion regulation, such that people who are less upset by a stressful event will experience a smaller increase in distress than someone who is more upset by a stressful event (Almeida, 2005; Bolger \& Zuckerman, 1995). 
Researchers posit that receiving poor parenting in childhood may serve as a vulnerability factor-resulting in poorer emotion regulation skills, which in turn lead to worse emotional outcomes (e.g., Lehman et al., 2009). In the present study, we assessed whether retrospective reports of low-quality mother-child and father-child relationships are related to higher levels of stressor exposure and greater stressor reactivity.

\section{Neuroticism}

A concern with using self-reported information is possible response bias. Researchers have suggested that neuroticism captures a negative response bias whereby people report higher levels of negative emotions and more somatic complaints (e.g., Watson \& Pennebaker, 1989). High levels of neuroticism have also been linked to more pronounced mood swings and to greater reactivity to stressors (Mroczek \& Almeida, 2004; Suls, Green, \& Hillis, 1998; Suls \& Martin, 2005). To alleviate this concern, researchers often include neuroticism in their statistical models to control for potential negative response biases driving their results (e.g., Charles \& Almeida, 2007). In the present study, a negative response bias would lead to more negative childhood memories, a greater reported number of daily stressors, and higher levels of psychological distress. Thus, we included neuroticism in our models to reduce the risk that the relationship between retrospective reports of mother-child and father-child relationship quality and daily emotional experiences during adulthood is a function of distorted or biased reporting.

\section{The Present Study}

The current study examined how retrospective accounts of mother-child and father-child relationship quality during childhood are related to daily emotional experiences (e.g., psychological distress), stressor exposure, and emotional reactivity to stressful events. We hypothesized that more positive retrospective ratings of early mother-child and father-child relationship quality are related to lower levels of daily psychological distress. In addition, we hypothesized that more positive ratings of early relationship quality are related to experiencing fewer daily stressors in adulthood. Finally, we predicted that more positive retrospective ratings of early relationship quality with mothers and fathers are related to decreased emotional reactivity to daily stressors. We further predicted that this relationship would be stronger for fathers and sons.

In addition, we queried whether our findings would vary by age group. Given that our data included a wide age range of people who were children from the 1920s to the 1970s and given evidence indicating that parenting practices may have varied across historical periods in the United States, we examined whether the hypotheses varied by respondents' age cohort.

In all analyses, we controlled for several covariates. In addition to neuroticism, we controlled for SES. As indicated earlier, low SES in childhood has been associated with poorer parental quality, poorer health in adulthood, and low SES in adulthood. For this reason, we included both childhood SES and adulthood SES in our models. Additionally, we controlled for the possibility that individuals whose parents had died would have different memories than those whose parents were alive; thus, we also controlled for survival status of the parent (i.e., whether respondents' mothers and fathers were living or deceased) in our analyses.

\section{Methods}

\section{Participants and Procedure}

Respondents participated in the National Study of Daily Experiences (NSDE), a daily diary study included in the National Survey of Midlife in the United States (MIDUS) (Brim, Ryff, \& Kessler, 2004) and performed under the auspices of the John D. and Catherine T. MacArthur Foundation Research Network on Successful Midlife Development (Orville Gilbert Brim, Director). The MIDUS survey was administered to a nationally representative sample of 7,189 noninstitutionalized adults (age range $=25$ to 74 years) recruited by telephone to participate in the study (for further information, please see Brim et al., 2004).

Of the 1,242 original randomly selected MIDUS respondents for the NSDE, 1,031 (562 women, 469 men) chose to participate, for a response rate of $83 \%$. Respondents completed short telephone interviews about their daily experiences in the past $24 \mathrm{hr}$ on 8 consecutive evenings. They completed an average of seven of the eight interviews, resulting in a total of 7,221 daily interviews. Data collection spanned an entire year and consisted of 40 separate flights of interviews, with each flight representing the 8-day sequence of interviews from approximately 38 respondents. The initiation of interview flights was staggered across the day of the week to control for possible confounding between day of the study and day of the week.

Approximately half of the NSDE sample were women (54.5\%), and over half of the sample had at least a high school degree or equivalent $(62 \%)$. The average family income was between $\$ 50,000$ and $\$ 55,000$. The NSDE sample was predominately Caucasian $(90.3 \%)$, with a small subsample of African Americans $(5.9 \%)$; the remainder reported they were from other racial groups, or they declined to state their ethnicity (3.8\%). Most reported being married $(65.4 \%)$ and a large percentage reported having at least one child age 18 or under living in the household $(37.8 \%)$. For the current study, only respondents who reported on both maternal and paternal relationship quality were included in the analyses ( $N=912$; men: $n=423$, women: $n=489)$. This exclusion criterion was selected to examine the unique contribution of each parent for all people where information from both parents was available.

\section{Measures}

Mother-child and father-child relationship quality. In the MIDUS questionnaire, respondents rated the quality of their relationships with both their mother and father during childhood. Participants first rated the overall relationship quality with their mother in response to the question, "How would you rate your relationship with your mother during the years when you were growing up?" Participants responded on a Likert-type scale ranging from 1 (excellent) to 5 (poor). Respondents then answered the following questions: "How much did she understand your problems or worries?" "How much could you confide in her about things that were bothering you?" "How much love and affection did she give you?" "How much time and attention did she give 
when you needed it?" "How much effort did she put into watching over you and making sure you had a good upbringing?" "How much did she teach you about life?" Participants responded on a Likert-type scale ranging from 1 to 4 corresponding to 1 (a lot), 2 (some), 3 (a little), and 4 (not at all). Identical questions were then asked about their father. To provide an equivalent measurement scale across all five of these questions, responses to the first question were multiplied by .75. All scores were reverse coded so that higher scores indicate higher quality, and mean scores were calculated for mother-child relationship quality $(\alpha=.91)$ and father-child relationship quality $(\alpha=.93)$. For additional studies using this measure, see Davey, Tucker, Fingerman, and Savla (2009) and Rossi (2001).

Daily psychological distress. Daily psychological distress was assessed with the Non-Specific Psychological Distress Scale developed for the MIDUS survey (Kessler et al., 2002; Mroczek \& Kolarz, 1998). This measure included self-reported assessments of how much during the past $24 \mathrm{hr}$ the respondent reported feeling the following: depressed, restless or fidgety, so restless that [the respondent] could not sit still, nervous, so nervous that nothing could calm [the respondent] down, worthless, so sad that nothing could cheer [the respondent] up, tired out, that everything was an effort, and hopeless. Responses were based on a 5-point scale from 1 (none of the time) to 5 (all of the time). A daily psychological distress score was created by computing the mean scores across the 10 items $(\alpha=.89)$. For additional studies using this measure, see Almeida et al. (2002).

Daily stressors. Daily stressors were assessed through the semi-structured Daily Inventory of Stressful Events (Almeida et al., 2002). The inventory consisted of a series of stem questions asking whether six types of stressor events (arguments or disagreements, avoided arguments and tensions, home events, work events, events occurring to the respondent's close other, and discrimination) occurred within the previous $24 \mathrm{hr}$ along with a set of guidelines for probing affirmative responses. The aim of the interviewing technique was to acquire a short narrative of each event that was then used to rate various components of the events. For example, if respondents said that a work stressor had occurred, they were then asked follow-up questions, such as "Could you tell me a little about the background to that?" or "What about this do you think most people would consider stressful?" All interviews were tape-recorded and were then transcribed and coded for several characteristics, including type or classification. It should be noted that nonevents, or responses triggered by sad memories or recollections of the past, were not coded. For each of the six stressor stem questions included in the present study, people received a score of 1 if a stressor was reported and a score of 0 if no stressors were reported. The total number of stressors reported each day was averaged to capture individual differences in the average number of stressors (termed weekly stressor exposure) that people were exposed to across the course of the week. The daily stressors score was created by dummy coding study days into two categories, such that respondents were given a score of 1 if they provided an affirmative response to any of the stem questions and a score of 0 if they did not. Two expert raters coded approximately $20 \%$ of all the stressors. Respondents reported experiencing three stressors on average across the 8 days of the study. In terms of daily stressors, respondents reported any stressors on $40 \%$ of the study days. The Daily Inventory of Stressful Events has strong reliability and validity (Almeida et al., 2002) and has been used effectively in many previous studies (e.g., Grzywacz, Almeida, Neupert, \& Ettner, 2004; Mallers, Almeida, \& Neupert, 2005).

Neuroticism. Neuroticism was assessed in the MIDUS questionnaire by a four-item measure created for the MIDUS (Lachman \& Weaver, 1997). Participants rated how well the items moody, worrying, nervous, and calm (reversed) described them on a 0 through 3 response scale $(0=$ not at all and $3=a$ lot $)$. The mean was then taken for these items (leaving out those who had missing data for one or more items). Coefficient alpha was .79 in the current sample. This scale has been used in a number of published reports that have documented its construct validity (Mroczek \& Kolarz, 1998; Prenda \& Lachman, 2001; Staudinger, Fleeson, \& Baltes, 1999).

Childhood and current SES. We used the highest education level of the father as an indicator of childhood SES (Almeida, Neupert, Banks, \& Serido, 2005). Parental education is a welldefined gradient of socioeconomic disadvantage (Adler et al., 1994; Marmot, Ryff, Bumpass, Shipley, \& Marks, 1997) and the foundation from which occupational and earning strata are created (N. F. Marks \& Shinberg, 1998). When information about the father's education was not available, we used the highest education of the mother. We included this measure because childhood SES is a significant correlate of parenting quality (Shaw et al., 2004). People reported the highest level of education achieved by their father, followed by an identical question about the educational attainment of their mother on a 12-point ordinal scale, ranging from 1 (no school or some grade school) to 12 (doctoral or other professional degree). For current SES, respondents reported their highest level of education achieved on a 12-point ordinal scale, ranging from 1 (no school or some grade school) to 12 (doctoral or other professional degree).

Mother and father survival status. The MIDUS survey asked respondents if their father and mother were still alive $(1=$ yes, $0=$ no). A dichotomous variable was created indicating the survival status of each parent.

\section{Results}

\section{Descriptive Results}

Table 1 presents descriptive information and correlations among the study variables. Mother-child relationship quality and fatherchild relationship quality were significantly related to one other, but the zero-order correlation coefficient of .46 suggested unique components for each construct. A repeated measures general linear model compared mother-child quality with father-child relationship quality and examined whether these ratings varied by gender and age group of the participants. To examine possible historical variations in parent-child relationships, we created five categorical age groups, broken into decades, including people born between 1921 and 1970: (a) ages 25-34 years, (b) ages 35-44 years, (c) ages 45-54 years, (d) ages 55-64 years, and (e) ages 65-74 years. In all of the analyses, the oldest age group served as the referent group. Results indicate that mother-child relationship quality $(M=3.17, S E=0.02)$ was rated significantly higher than father-child relationship quality $(M=2.81, S E=0.03), F(1$, $910)=177.43, p<.001 ; \eta^{2}=.17$. An interaction between relationship type (mother vs. father) and gender was significant, 
Table 1

Descriptive Statistics and Intercorrelations for Study Variables at the Between-Person Level

\begin{tabular}{|c|c|c|c|c|c|c|c|c|c|c|c|c|c|}
\hline Variable & $M$ & $S D$ & 1 & 2 & 3 & 4 & 5 & 6 & 7 & 8 & 9 & 10 & 11 \\
\hline 1. Mother relationship quality & 3.13 & 0.68 & - & & & & & & & & & & \\
\hline 2. Father relationship quality & 2.77 & 0.78 & $.46^{\text {***** }}$ & - & & & & & & & & & \\
\hline 3. Daily distress & 1.86 & 2.99 & $-.24^{* * * *}$ & $-.15^{* * * *}$ & - & & & & & & & & \\
\hline 4. Stressor exposure & 0.49 & 0.43 & $-.19^{* * * *}$ & $-.18^{* * *}$ & $.33^{* * * *}$ & - & & & & & & & \\
\hline 5. Neuroticism & 3.95 & 0.35 & -.00 & -.03 & .01 & .04 & - & & & & & & \\
\hline 6. Gender & 1.55 & 0.50 & $-.15^{* * * *}$ & -.02 & .03 & $.06^{*}$ & .04 & - & & & & & \\
\hline 7. Mother survival status & 0.65 & 0.48 & $-.11^{* * *}$ & -.04 & .04 & $.15^{* * * * *}$ & .01 & .02 & - & & & & \\
\hline 8. Father survival status & 0.45 & 0.50 & .00 & -.05 & $.09^{* * *}$ & $.14^{* * * * *}$ & .04 & .00 & $.43^{* * * *}$ & - & & & \\
\hline 9. Childhood SES & 4.77 & 2.99 & .03 & $.08^{* *}$ & -.04 & $.19^{* * * * *}$ & .02 & .02 & $.21^{* * * *}$ & $.25^{* * * *}$ & - & & \\
\hline 10. Current SES & 6.86 & 2.32 & $.06^{*}$ & .02 & $-.18^{* * * *}$ & $.10^{* * *}$ & $.07^{*}$ & $-.09^{* *}$ & .06 & .07 & $.40^{* * * *}$ & - & \\
\hline 11. Age & 47.35 & 13.15 & .05 & $.08^{*}$ & $-.11^{* * * *}$ & $-.23^{* * * *}$ & -.06 & .01 & $-.58^{* * * *}$ & $-.59^{* * * *}$ & $-.28^{* * *}$ & -.01 & - \\
\hline
\end{tabular}

Note. Because weekly stressor exposure is the same as daily stressor exposure at the between-person level, we only report the daily stressor exposure statistics. SES $=$ socioeconomic status.

${ }^{*} p<.05$. ** $p<.01$. *** $p<.001$.

$F(1,910)=9.30, p<.001 ; \eta^{2}=.01$. This interaction revealed that men reported higher ratings of mother-child quality than did women (men: $M=3.26, S E=0.04$; women: $M=3.07, S E=$ $0.04)$ but reported similar ratings for father-child relationship quality (men: $M=2.82, S E=0.04$; women: $M=2.79, S E=$ 0.04). In addition, a significant age group main effect, $F(1,910)=$ $4.29, p<.01 ; \eta^{2}=.02$, revealed that overall relationship quality was highest for the two oldest cohorts of adults, those ages 55-64 years $(M=3.08, S E=0.04)$ and those ages $65-74$ years $(M=$ $3.10, S E=0.07)$, compared with people ages $25-34$ years $(M=$ 2.97, $S E=0.05)$ and those ages $45-54$ years $(M=2.91, S E=$ $0.04)$. The age/cohort group ages 35-44 years had significantly lower ratings $(M=2.87, S E=0.04)$ compared with all other age groups with the exception of those ages 45-54 years. As a result, we controlled for age group and also explored age group interaction with the hypotheses. Furthermore, on the basis of prior research, we also controlled for childhood SES, current SES, levels of neuroticism, and survival status of both the mother and the father.

\section{Multilevel Analyses}

We used multilevel modeling with the SAS Proc Mixed program to examine emotional reactivity to daily stressors. In this framework, individual change/variability is represented by a twolevel hierarchical model (J. D. Hawkins, Guo, Hill, Battin-Pearson, \& Abbott, 2001). At Level 1, each person's variability is expressed as an individual regression equation with its own intercept and slope. These individual parameters become the outcome variables in a Level 2 model, where person-level characteristics can be included to explain individual differences. Multilevel modeling is frequently used to model intraindividual variability, that is, people's variability around their own average. This technique was useful in the current study because we examined interindividual differences (e.g., mother-child and father-child relationship quality) in intraindividual covariation (e.g., the within-person relationship between stressors and psychological distress).

\section{Multilevel Results}

We examined whether sufficient variance existed both within person (Level 1) and between person (Level 2) to include predic- tors in the model. Fully unconditional models revealed that the amount of variance differed significantly from 0 , such that $54 \%$ of the variability in emotional distress was between people, $\tau_{00}=$ $7.22, z=19.42, p<.001$, and $46 \%$ was within people, $\sigma^{2}=6.23$, $z=55.35, p<.001$. Thus, we proceeded to examine variables that accounted for this between- and within-subject variance in tests of the hypotheses (Nezlek, 2001; Raudenbush \& Bryk, 2002).

Daily psychological distress and mother-child and fatherchild relationship quality. We hypothesized that more positive retrospective ratings of early mother-child and father-child relationship quality would be related to lower levels of daily psychological distress. In a multilevel model, psychological distress was the dependent variable and both mother-child and father-child relationship quality were entered as independent variables. The covariates included age group, neuroticism, childhood and adulthood SES, mother survival status, father survival status, and gender (see Model 1 in Table 2). Results showed that mother-child relationship quality was significantly related to psychological distress $\left(\gamma_{012}\right)$, indicating that higher levels of reported mother-child relationship quality were related to lower levels of daily psychological distress. For example, people who reported high levels of mother-child relationship quality (the mean plus one standard deviation) reported 3\% less psychological distress compared with those who reported low levels of mother-child relationship quality (the mean minus one standard deviation). Across the covariates, higher levels of neuroticism $\left(\gamma_{001}\right)$, lower current SES $\left(\gamma_{002}\right)$, mother survival status $\left(\gamma_{006}\right)$, and younger age $\left(\gamma_{008}\right.$ and $\left.\gamma_{009}\right)$ were significantly associated with higher levels of daily psychological distress. Although the zero-order correlation of fatherchild relationship quality and psychological distress was significant (in Table 1), this association was not significant in this model with the inclusion of the other variables. The model explained $47 \%$ of the between-person variance in psychological distress.

We explored whether gender would interact with either motherchild or father-child relationship quality, for example, whether the relationship between mother-child relationship quality and psychological distress would be stronger for women than for men and whether the relationship between father-child relationship quality and psychological distress would be stronger for men than for women. Although the interaction between gender and father-child relationship quality showed a trend in which higher levels of 
Table 2

Coefficients (and Standard Errors) of Multilevel Models of Daily Psychological Distress

\begin{tabular}{|c|c|c|c|}
\hline Fixed effect & Model 1 & Model 2 & Model 3 \\
\hline \multicolumn{4}{|l|}{ Psychological distress, $\beta_{0}$} \\
\hline Intercept, $\gamma_{000}$ & $-0.39(0.43)$ & $-0.56(0.40)$ & $-0.54(0.40)$ \\
\hline Neuroticism, $\gamma_{001}$ & $1.29^{* * * *}(0.12)$ & $1.18^{* * * *}(0.11)$ & $1.18^{* * * *}(0.11)$ \\
\hline Current SES, $\gamma_{002}$ & $-0.14^{* * * *}(0.04)$ & $-0.18^{* * * *}(0.04)$ & $-0.18^{* * * *}(0.04)$ \\
\hline Childhood SES, $\gamma_{003}$ & $-0.01(0.03)$ & $-0.03(0.03)$ & $-0.03(0.03)$ \\
\hline Gender, $\gamma_{004}$ & $0.08(0.15)$ & $0.20(0.15)$ & $0.11(0.16)$ \\
\hline Total stress, $\gamma_{005}$ & - & $0.14^{* * * *}(0.03)$ & $0.14^{* * * *}(0.03)$ \\
\hline Mother alive, $\gamma_{006}$ & $-0.38(0.19)$ & $-0.38^{*}(0.19)$ & $-0.38 *(0.19)$ \\
\hline Father alive, $\gamma_{007}$ & $0.09(0.19)$ & $0.08(0.18)$ & $0.06(0.18)$ \\
\hline Ages $25-34, \gamma_{008}$ & $0.78 *(0.36)$ & $0.52(0.34)$ & $0.52(0.34)$ \\
\hline Ages $35-44, \gamma_{009}$ & $0.79 *(0.33)$ & $0.46(0.31)$ & $0.45(0.31)$ \\
\hline Ages $45-54, \gamma_{010}$ & $0.40(0.31)$ & $0.21(0.29)$ & $0.18(0.29)$ \\
\hline Ages $55-64, \gamma_{011}$ & $-0.09(0.30)$ & $-0.12(0.28)$ & $-0.14(0.28)$ \\
\hline Mother relationship quality, $\gamma_{012}$ & $-0.56^{* * *}(0.14)$ & $-0.43^{* *}(0.14)$ & $-0.55^{* *}(0.17)$ \\
\hline Father relationship quality, $\gamma_{013}$ & $-0.06(0.12)$ & $0.13(0.12)$ & $0.21(0.15)$ \\
\hline Gender $\times$ Mother Relationship Quality, $\gamma_{014}$ & & & $0.37(0.29)$ \\
\hline Gender $\times$ Father Relationship Quality, $\gamma_{015}$ & & & $-0.22(0.24)$ \\
\hline \multicolumn{4}{|l|}{ Daily stressor/reactivity slope, $\beta_{1}$} \\
\hline Intercept, $\gamma_{10}$ & & $1.20^{* * * *}(0.08)$ & $1.15^{* * * *}(0.10)$ \\
\hline Mother relationship quality, $\gamma_{11}$ & & $-0.10(0.13)$ & $-0.14(0.16)$ \\
\hline Father relationship quality, $\gamma_{12}$ & & $-0.29^{* *}(0.11)$ & $-0.11(0.14)$ \\
\hline Gender, $\gamma_{13}$ & & & $0.12(0.15)$ \\
\hline Gender $\times$ Mother Relationship Quality, $\gamma_{14}$ & & & $0.04(0.28)$ \\
\hline Gender $\times$ Father Relationship Quality, $\gamma_{15}$ & & & $-0.49 *(0.23)$ \\
\hline \multicolumn{4}{|l|}{ Random effects } \\
\hline Level of distress $\left(\tau_{00}\right)$ & $3.82^{* * * *}$ & $3.31^{* * * *}$ & $3.28^{* * * * *}$ \\
\hline Within-person fluctuation $\left(\sigma^{2}\right)$ & $5.74^{* * * * *}$ & $5.47^{* * * *}$ & $5.47^{\text {***** }}$ \\
\hline
\end{tabular}

Note. $\quad$ SES $=$ socioeconomic status.

${ }^{*} p<.05 . \quad{ }^{* * *} p<.01 .^{* * * *} p<.001$.

father-child relationship quality were related to lower levels of psychological distress among men, $t(4815)=-1.89, p=.06$, this trend was not significant. We also explored in an additional model the interactions between the five age categories and father-child and mother-child relationship quality and whether these relationships were stronger for different age groups. No interactions with age and either parental relationship quality variable approached levels of significance (e.g., $t$ values ranged from 0.13 to 1.56 ).

Stressor exposure and mother-child and father-child relationship quality. We hypothesized that more negative retrospective ratings of mother-child and father-child relationship quality were also related to greater exposure to daily stressors. In a regression analysis, we used the average number of stressor categories reported each day (maximum of six each day) across the 8 days as the dependent variable. Mother-child and father-child relationship quality were the independent variables, and age group, childhood and current SES, gender, neuroticism, and the survival statuses of the mother and the father were included as covariates. Results indicated that poorer relationship quality with both mother $(\beta=-.08, p=.05)$ and father $(\beta=-.12, p=.003)$ were associated with more stressors. People who reported low levels of mother-child relationship quality (the mean minus one standard deviation) reported 3\% more stressors compared with those who reported higher levels of mother-child relationship quality (the mean plus one standard deviation), and those who reported lower levels of father-child relationship quality (the mean minus one standard deviation) reported $4 \%$ more stressors compared with those who reported higher levels of father-child relationship qual- ity (the mean plus one standard deviation). In addition, higher childhood SES and current SES, younger age, and higher levels of neuroticism were significantly related to a greater numbers of stressors reported across the 8-day study. The total model accounted for $12 \%$ of the variance in average stressor exposure.

Emotional reactivity and mother-child and father-child relationship quality. We hypothesized that mother-child and father-child relationship quality were each related to emotional reactivity to daily stressors. We examined this prediction in a single multilevel model in which psychological distress was the dependent variable. In this model (see Model 2 in Table 2), mother-child and father-child relationship quality, the occurrence of a stressor that day, and the interactions between mother-child relationship quality and stressor occurrence and between father-child relationship quality and stressor occurrence were included with the covariates (i.e., childhood and current SES, age category, gender, neuroticism, and both mother and father survival status). Total number of stressors also was included as a covariate in this model to ensure that stressor occurrence was uniquely capturing the effect of that stressor on the psychological distress experienced that day and was not capturing the effects of greater overall stressor exposure on psychological distress. The hypotheses regarding reactivity were tested by the interaction between stressor occurrence and mother-child relationship quality $\left(\gamma_{11}\right)$, and the interaction between stressor occurrence and father-child relationship quality $\left(\gamma_{12}\right)$. Results revealed that higher reported father-child relationship quality in childhood was significantly associated 
with less reactivity to daily stressors (see Figure 1). The interaction with mother-child relationship quality was not significant. This model accounted for $12 \%$ of the within-person and $54 \%$ of the between-person variance in daily psychological distress. We also tested the hypothesis that father-son relationship quality would be related to stressor reactivity, such that men who reported higher relationship quality with their fathers would be less emotionally reactive to daily stressors than men who reported lower relationship quality (see Model 3 in Table 2 ). Results support our hypothesis, such that the buffering effect of higher levels of father-child relationship quality on reactivity to stressors was significant only among men $\left(\gamma_{15}\right)$; for women, father-child relationship quality was unrelated to stressor reactivity. This model accounted for $12 \%$ of the withinperson and $55 \%$ of the between-person variance in daily psychological distress.

We explored whether these effects were stronger for age group in a third model that included the three-way interaction of fatherchild relationship quality, stressor exposure, and age. Given the exploratory nature of these analyses, we set the significance criterion to $p<.01$. None of the interactions with the five age categories were significant.

\section{Discussion}

Most studies examining parenting received in childhood focus on the relationship with the mother (e.g., Bowlby, 1982). Growing evidence, however, suggests that fathers play a unique and important role in the health of their offspring (e.g., Lamb, 2004; Nord, Brimhall, \& West, 1997; Tamis-LeMonda, Shannon, Cabrera, \& Lamb, 2004). The current study examined the unique associations between retrospective reports of mother-child and father-child relationship quality during childhood and daily emotional experiences (psychological distress), stressor exposure, and reactivity to stressors during adulthood. Findings reveal that only mother-child relationship is significantly related to overall levels of emotional experience in analyses where both relationships are examined together. When examining associations with daily stressors and reports of parent-child relationship quality, relationship quality with both mother and father are each uniquely associated with

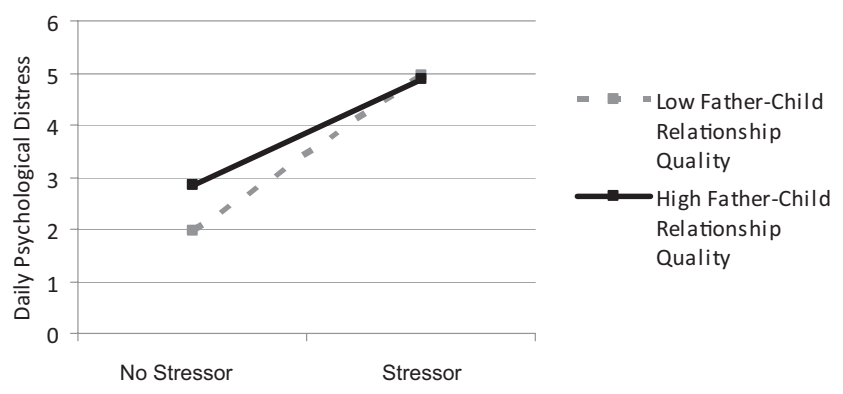

Figure 1. Father-child relationship quality differences in emotional reactivity to daily stressors. Those with a high-quality father-child relationship (the mean plus one standard deviation) were less reactive to daily stressors than those with a low-quality father-child relationship (the mean minus one standard deviation). Results are adjusted for neuroticism, childhood socioeconomic status, current socioeconomic status, total stress, parent survival status, and age group. stressor exposure. However, only father-child relationship quality is significantly related to emotional reactivity to stressors and only among men.

\section{Mother-Child Relationship Quality and Levels of Daily Psychological Distress}

We hypothesized that more positive retrospective ratings of early mother-child and father-child relationship quality would each be related to lower levels of daily psychological distress. Both relationship reports were independently related to lower levels of daily psychological distress; however, only mother-child relationship quality remained a unique predictor of psychological distress when both mother-child and father-child relationship quality were included in a model together. This finding was true for both men and women.

The importance of mother-child relationship quality for both men and women on daily levels of psychological distress is consistent with the attachment literature that states that mothers traditionally serve as the primary caregiver from whom the initial parent-child bond is established, one that provides physical safety and comfort for both girls and boys (Ainsworth, 1973; Bowlby, 1969). During times of stress, the mother is the parent who most often attempts to calm and reassure children (Paquette, 2004). Thus, the mother-child relationship serves as a salient foundation from which both men and women develop their secure base and thus their general emotional well-being. This appears to hold true across a wide age range of adults raised in different historical eras. Thus, regardless of both gender and cohort, reports of higher mother-child relationship quality are related to lower levels of daily distress in adulthood.

\section{Mother-Child and Father-Child Relationship Quality and Exposure to Daily Stressors}

Although only the mother-child relationship quality was uniquely associated with overall levels of psychological distress, both mother-child and father-child relationship quality were each significantly associated with daily stressor occurrence. Although daily stressors may be unpredictable, more often they arise out of the routine circumstances of everyday life (Almeida, 2005). Psychosocial characteristics likely play a role in determining what kinds of stressors an individual experiences (Almeida, 2005), such as early parent-child relationship quality.

Research has shown that support from parents during childhood has significant and lasting implications for well-being (Antonucci \& Akiyama, 1987; Shaw et al., 2004). It is interesting that the majority of daily stressors are interpersonal arguments and tensions, as compared with work/school, home, health-related, or network stressors (stressful events happening to a close other of the respondent; Almeida, 2005), and are highly predictive of psychological distress. Perhaps having attentive and caring parents equips children with the experiences and skills necessary to more successfully navigate their relationships with other people throughout childhood and into adulthood as compared with those without such sensitive parents. In other words, having a healthy parent-child relationship may buffer both men and women from exposure to daily stressors that involve interactions with others. 


\section{Father-Child Relationship Quality and Emotional Reactivity to Stressors}

Having received high-quality parenting from both parents in childhood may serve as a buffer from which adult children experience daily stressors, but only reports of father-child relationships were significantly associated with stressor reactivity and only among men. Men who reported having had higher quality fatherchild relationships during childhood reported less emotional reactivity to daily stressors compared with men who reported having poorer father-child relationship quality. This finding held even after controlling for neuroticism, childhood and current SES, age, and survival status of both parents. Thus, for men, although the mother-son relationship is related to overall levels of daily distress, the father-child relationship is more relevant in influencing how they emotionally react to the stressors in their everyday lives.

One possible reason for this finding is that men were socialized by their fathers to be stern and stoic and not express emotion. This stoicism may, in turn, lead them to report less emotional reactivity to these stressors. A problem with this explanation, however, is that this association held across adults of all ages in the study, representing men who were raised during different historical eras in the United States. If this finding was driven by fathers inculcating stoicism among their sons, we might expect this finding to be stronger among the older cohorts, raised at a time in history when stereotypes that men not express their emotions to others were more strongly endorsed (Lamb, 2004).

Another potential explanation for the role of father-son relationship quality buffering the effects of daily stressors on emotional experience is that men may interact with their sons in ways that prepare them for stressful, problem-solving situations. As we discussed previously, fathers may be particularly influential in the development of certain aspects of child behavior and, in particular, for the behavior of sons. When fathers are active with their children, they generally spend more time with their sons than with their daughters and engage them in play and competitive activities; mothers, in contrast, spend an equal amount of time with boys and girls (Aldous et al., 1998; Harris \& Morgan, 1991). Furthermore, physically active play behaviors, such as roughhousing, talking, and recreational activities place more problem-solving related demands on the sons (Lamb, 1997) and teach them to regulate emotions (Paquette, 2004). Play is considered essential for developing children's problem-solving capacity, social competence, social efficacy, and interpersonal cognition in peer interaction (see Liu, 2008). Children of involved fathers are more likely to demonstrate a greater tolerance for stress and frustration and to be more resourceful and skillful when presented with a problem (Biller, 1993; Easterbrooks \& Goldberg, 1990; Mischel et al., 1988). Perhaps a reason why this same relationship was not found for women is that fathers may be more sensitive to the emotions of their daughters than their sons. This sensitivity may have the unintended effect of not modeling effective emotional regulation in the face of stressful experiences. In contrast, fathers may be more likely to push their sons to participate in challenging and sometimes perhaps difficult situations that enhance competence and psychological adjustment (e.g., Amato, 1994; Fagan \& Iglesias, 1999; Yogman, Kindlon, \& Earls, 1995).

These findings suggest that future research efforts need to focus on understanding how both fathers and mothers influence long- term well-being for their children. Previous studies have been complicated by the fact that there is no singular set of guidelines that define what is good fathering. Furthermore, studies that have examined the role of fathers often note negative actions on the part of fathers and not how their positive actions may be related to long-term outcomes for their children (L. D. Marks \& Palkovitz, 2004). In addition, greater emphasis can also be placed on understanding how fathers, whether unconsciously or not, parent in ways that lead to differential treatment for their sons and daughters.

\section{Limitations and Future Research Directions}

Findings about mother-child and father-child relationship quality during childhood were based on retrospective reports, with some respondents recalling childhood experiences over 50 years and more. This methodology raises concerns that perceptions may change over time or that positive or negative response biases may be driving the findings. Previous studies, however, have indicated that one's viewpoint and beliefs of recalled experiences with parents are strong predictors of psychological well-being throughout life (Russek \& Schwartz, 1997; Shumaker \& Czajkowski, 1994). In addition, longitudinal studies following children into adulthood have found that reports of perceived warmth in adulthood are consistent with what researchers observed when these adults were children (Brewin \& Gotlib, 1993; Parker, Turpling, \& Brown, 1979). Even if these perceptions are not accurate representations of childhood experiences, they nevertheless suggest that how people remember the parenting they received in childhood from their mother and their father is significantly and differentially related to their emotional experiences in adulthood.

Concerning the possibility of a response bias driving the findings, the differential patterns of findings for mother-child and father-child relationship quality to stressor and emotional outcomes in the current study help to allay these concerns. If happier people, for example, reported all aspects of their lives more positively and reported less emotional reactivity when stressors occurred (and vice versa for less happier people), then we would not expect differential patterns on the basis of the gender of the parent or the gender of the respondent. Longitudinal data, observing or querying children and following them until the oldest are 74 years old, will allow us to either confirm or dispute the inferences from this study. Until these data are available, these findings suggest that both mother-child and father-child relationship quality are associated with the emotional well-being of children long after childhood is over.

Another limitation is that our current study included only people who reported on parent-child relationship quality from both mother and father. We limited our study to examine the unique role of the mother and father when both parents were present in the respondent's childhood; thus, this research necessarily excluded people who were raised in households where children were not parented by both a mother and a father. Families headed by same-sex parents, for example, may show very different patterns of influences on parent-child relationships (Arnup, 1995; Barrett \& Tasker, 2001; Martin, 1998; Morris, Balsam, \& Rothblum, 2002).

In addition, future studies should examine the relationship between mother-child and/or father-child relationships during 
childhood and adulthood outcomes among different ethnic and socioeconomic groups. For example, research shows that income is positively correlated with father involvement among groups varying by ethnicity and SES (Fagan, 1998; Honig \& Mayne, 1982; Parke, 1996). Such findings may shed light on variations of parenting and parenting practices, as well as on perceptions of parental involvement. Moreover, in-depth qualitative studies would greatly help researchers understand parental relationship quality and reactivity to stress in ways that large-scale survey studies (and especially retrospective studies) cannot capture.

Finally, the present study did not measure potential mechanisms underlying associations between mother-child and father-child relationships quality and both psychological distress and reactivity. Possible mechanisms include biobehavioral and physiological/ neuroendocrine pathways linking poor parenting quality during childhood and the increased risk for mental health disorders later in life (for a review, see Repetti et al., 2002; Taylor et al., 2004). Also, children develop relationship schemas from their parental attachments, which serve as an internalized working model for all future relationships; these are "templates that serve as guides for interpreting emotions, perceptions, and behaviors in all future relationships" (Honig, 2002, p. 4). The more distal factors of parental relationship quality, then, may have set the stage for current relationships that influence daily emotional experience and reactivity. Again, only longitudinal studies can establish the temporal relationships of these mechanisms that potentially link childhood experiences to later emotion-related outcomes.

\section{Conclusion}

Limitations notwithstanding, the current study is the first to examine the interaction between relationships with parents during childhood and psychological distress and stressor reactivity in adulthood. Findings suggest that mother-child relationship quality continues to shape overall levels of emotional experience in daily life. These findings also underscore the importance of fathers in the lives of their sons and indicate that assessments of emotional experience that move beyond overall levels of emotional well-being may uncover further influences of both mothers and fathers on the enduring emotional experiences of their children.

\section{References}

Adler, N. E., Boyce, T., Chesney, M. A., Cohen, S., Folkman, S., Kahn, R. L., \& Syme, S. L. (1994). Socioeconomic status and health: The challenge of the gradient. American Psychologist, 49, 15-24. doi: 10.1037/0003-066X.49.1.15

Ainsworth, M. D. (1973). The development of infant-mother attachment. In B. M. Caldwell \& H. N. Ricciuti (Eds.), Review of child development research (Vol. 3, pp. 1-94). Chicago, IL: University of Chicago Press.

Aldous, J., Mulligan, G., \& Bjarnason, T. (1998). Fathering over time: What makes the difference? Journal of Marriage and the Family, 60, 809-820. doi: $10.2307 / 353626$

Almeida, D. (2005). Resilience and vulnerability to daily stressors assessed via diary methods. Current Directions in Psychological Science, 14, 64-68. doi:10.1111/j.0963-7214.2005.00336.x

Almeida, D. M., Neupert, S. D., Banks, S. R., \& Serido, J. (2005). Do daily stress processes account for socioeconomic health disparities? Journal of Gerontology: Social Sciences, 60B, 34-39.

Almeida, D. M., Wethington, E., \& Kessler, R. C. (2002). The Daily
Inventory of Stressful Events: An interview-based approach for measuring daily stressors. Assessment, 9, 41-55.

Amato, P. R. (1986). Father involvement and the self-esteem of children and adolescents. Australian Journal of Sex, Marriage and Family, 7, $6-16$.

Amato, P. R. (1994). Father-child relations, mother-child relations, and offspring psychological well-being in early adulthood. Journal of Marriage and the Family, 56, 1031-1042. doi:10.2307/353611

Antonucci, T. C., \& Akiyama, H. (1987). Social networks in adult life and a preliminary examination of the convoy model. Journal of Gerontology, $42,519-527$

Antonucci, T. C., Akiyama, H., \& Takahashi, K. (2004). Attachment and close relationships across the life span. Attachment and Human Development, 6, 353-370. doi:10.1080/1461673042000303136

Aquilino, W. S. (1997). From adolescent to young adult: A prospective study of parent-child relations during the transition to adulthood. Journal of Marriage and the Family, 59, 670-686. doi:10.2307/353953

Arnup, K. (1995). Lesbian parenting: Living with pride and prejudice. Charlottetown, Prince Edward Island, Canada: Synergy Press.

Barrett, H., \& Tasker, F. (2001). Growing up with a gay parent: Views of 101 gay fathers on their sons' and daughters' experiences. Educational and Child Psychology, 18, 62-77.

Baumrind, D. (1980). New directions in socialization research. American Psychologist, 35, 639-652. doi:10.1037/0003-066X.35.7.639

Biller, H. B. (1974). Paternal deprivation. Lexington, MA: Heath.

Biller, H. B. (1993). Fathers and families: Paternal factors in child development. Westport, CT: Auborn House.

Biller, H. B., \& Solomon, R. S. (1986). Child maltreatment and paternal deprivation. Lexington, MA: Heath.

Blankenhorn, D. (1995). Fathers in America. New York, NY: Basic Books.

Bolger, N., DeLongis, A., Kessler, R. C., \& Schilling, E. A. (1989). Effects of daily stress on negative mood. Journal of Personality and Social Psychology, 57, 808-818. doi:10.1037/0022-3514.57.5.808

Bolger, N., \& Zuckerman, A. (1995). A framework for studying personality in the stress process. Journal of Personality and Social Psychology, 69, 890-902. doi:10.1037/0022-3514.69.5.890

Bowlby, J. (1969). Attachment and loss: Vol. 1. Attachment (2nd ed.). New York, NY: Basic Books.

Bowlby, J. (1982). Attachment and loss: Retrospect and prospect. American Journal of Orthopsychiatry, 52, 664-678. doi:10.1111/j.19390025.1982.tb01456.x

Brewin, C. R., \& Gotlib, A. H. (1993). Psychopathology and early experience: A reappraisal of retrospective reports. Psychological Bulletin, 113, 82-98. doi:10.1037/0033-2909.113.1.82

Brim, O. G., Ryff, C. D., \& Kessler R. (Eds.). (2004). How healthy are we? A national study of wellbeing in midlife. Chicago, IL: University of Chicago Press.

Charles, S. T., \& Almeida, D. M. (2007). Genetic and environmental effects on daily life stressors: More evidence for greater variation in later life. Psychology and Aging, 22, 331-340. doi:10.1037/08827974.22.2.331

Clarke-Stewart, K. A. (1978). And daddy makes three: The father's impact on mother and young child. Child Development, 49, 466-478. doi: $10.2307 / 1128712$

Coltrane, S. (2004). Fathering: Paradoxes, contradictions, and dilemmas. In M. Coleman \& L. Ganong (Eds.), Handbook of contemporary families: Considering the past, contemplating the future (pp. 224-243). Thousand Oaks, CA: Sage.

Davey, A., Tucker, C. J., Fingerman, K. L., \& Savla, J. S. (2009). Within-family variability in representations of past relationships with parents. Journals of Gerontology: Social Sciences, 64B, 125-136. doi: 10.1093/geronb/gbn001

Dempsey, K. (2000). Men's share of child care: A rural and urban comparison. Journal of Family Studies, 6, 245-266. 
Diehl, M., Elnick, A. B., Bourbeau, L. S., \& Labouvie-Vief, G. (1998). Adult attachment styles: Their relations to family context and personality. Journal of Personality and Social Psychology, 74, 1656-1669. doi:10.1037/0022-3514.74.6.1656

Doherty, W. J., Kouneski, E. F., \& Erickson, M. F. (1998). Responsible fathering: An overview and conceptual framework. Journal of Marriage and Family, 60, 277-292. doi:10.2307/353848

Easterbrooks, M., \& Goldberg, W. (1990). Security of toddler-parent attachment: Relation to children's sociopersonality functioning during kindergarten. In M. T. Greenberg (Ed.), Attachment in the preschool years: Theory, research, and intervention (pp. 221-244). Chicago, IL: University of Chicago Press.

Fagan, J. (1998). Correlates of low-income African American and Puerto Rican fathers' involvement with their children. Journal of Black Psychology, 24, 351-367. doi:10.1177/00957984980243006

Fagan, J., \& Iglesias, A. (1999). Father involvement program effects on fathers, father figures, and their Head Start children: A quasiexperimental study. Early Childhood Research Quarterly, 14, 243-269. doi:10.1016/S0885-2006(99)00008-3

Grzywacz, J. G., Almeida, D. M., Neupert, S. D., \& Ettner, S. (2004). Socioeconomic status and health: A micro-level analysis of exposure and vulnerability to daily stressors. Journal of Health and Social Behavior, 45, 274-288. doi:10.1177/002214650404500101

Harris, K., \& Morgan, S. (1991). Fathers, sons, and daughters: Differential paternal involvement in parenting. Journal of Marriage and the Family, 53, 531-544. doi: $10.2307 / 352730$

Hawkins, A. J., \& Dollahite, D. C. (1997). Generative fathering: Beyond the deficit perspective. Thousand Oaks, CA: Sage.

Hawkins, J. D., Guo, J., Hill, K. G., Battin-Pearson, S., \& Abbott, R. D. (2001). Long-term effects of the Seattle Social Development Intervention on school bonding trajectories. Applied Developmental Science, 5, 225-236.

Honig, A. S. (2002). Secure relationships: Nurturing infant/toddler attachment in early care settings. Washington, DC: National Association for the Education of Young Children.

Honig, A. S., \& Mayne, G. (1982). Black fathering in three social-class groups. Ethnic Groups, 4, 229-238.

House, J., Landis, K. R., \& Umberson, D. (1988, July 29). Social relationships and health. Science, 241, 540-545. doi:10.1126/science.3399889

Jacklin, C. N., DiPietro, J., \& Maccoby, E. (1984). Sex-typing behavior and sex-typing pressure in child/parent interaction. Archives of Sexual Behavior, 13, 413-425. doi:10.1007/BF01541427

Kanner, A. D., Coyne, J. C., Schaefer, C., \& Lazarus, R. S. (1981). Comparison of two modes of stress measurement: Daily hassles and uplifts versus major life events. Journal of Behavioral Medicine, 4, 1-39. doi:10.1007/BF00844845

Kessler, R., Andrews, G., Colpe, L., Hiripi, E., Mroczek, D., Normand, S., ... Zaslavsky, A. M. (2002). Short screening scales to monitor population prevalence and trends in non-specific psychological distress. Psychological Medicine, 32, 959-976. doi:10.1017/S0033291702006074

Labrell, F. (1996). Paternal play with toddlers: Recreation and creation. European Journal of Psychology of Education, 11, 43-54. doi:10.1007/ BF03172935

Lachman, M. E., \& Weaver, S. L. (1997). The Midlife Development Inventory (MIDI) personality scales: Scale construction and scoring (Technical report). Waltham, MA: Brandeis University, Department of Psychology.

Lamb, M. E. (1987). Introduction: The emergent American father. In M. E. Lamb (Ed.), The father's role: Cross-cultural perspectives (pp. 3-25). Hillsdale, NJ: Erlbaum.

Lamb, M. E. (1997). The role of the father in child development (3rd ed.). Hoboken, NJ: Wiley.

Lamb, M. E. (2004). The role of the father in child development (4th ed.). New York, NY: Wiley.
Lamb, M. E., Ketterlinus, R. D., \& Fracasso, M. P. (1992). Parent-child relationships. In M. H. Bornstein \& M. E. Lamb (Eds.), Developmental psychology: An advanced textbook (3rd ed., pp. 465-518). Hillsdale, NJ: Erlbaum.

Larsen, R. J., Billings, D. W., \& Cutler, S. E. (1996). Affect intensity and individual differences in informational style. Journal of Personality, 64, 185-207. doi:10.1111/j.1467-6494.1996.tb00819.x

Larsen, R. J., \& Kasimatis, M. (1990). Individual differences in entrainment of mood to the weekly calendar. Journal of Personality and Social Psychology, 58, 164-171. doi:10.1037/0022-3514.58.1.164

Lazarus, R. S., \& DeLongis, A. (1983). Psychological stress and coping process. New York, NY: McGraw-Hill.

Lazarus, R. S., \& Folkman, S. (1984). Stress, appraisal, and coping. New York, NY: Springer.

Lehman, B. J., Taylor, S. E., Kiefe, C. I., \& Seeman, T. E. (2009). Relationship of early life stress and psychological functioning to blood pressure in the CARDIA study. Health Psychology, 28, 338-346. doi: 10.1037/a0013785

Levine, J. A., Murphy, D. T., \& Wilson, S. (1993). Getting men involved: Strategies for early childhood programs. New York, NY: Scholastic.

Liu, Y. L. (2008). An examination of three models of the relationships between parental attachments and adolescents' social functioning and depressive symptoms. Journal of Youth and Adolescence, 37, 941-952. doi:10.1007/s10964-006-9147-1

Mallers, M. H., Almeida, D. M., \& Neupert, S. D. (2005). Women's daily physical health symptoms and stressful experiences across adulthood. Psychology and Health, 20, 389-403. doi:10.1080/08870440512331317698

Marks, L. D., \& Palkovitz, R. (2004). American fatherhood types: The good, the bad, and the uninterested. Fathering, 2, 113-129. doi:10.3149/ fth.0202.113

Marks, N. F., \& Shinberg, D. S. (1998). Socioeconomic status differences in hormone therapy. American Journal of Epidemiology, 148, 581-593.

Marmot, M., Ryff, C., Bumpass, L., Shipley, M., \& Marks, N. (1997). Social inequalities in health: Next questions and converging evidence. Social Science and Medicine, 44, 901-910. doi:10.1016/S02779536(96)00194-3

Martin, A. (1998). Clinical issues in psychotherapy with lesbian-, gay-, and bisexual-parented families. In C. J. Patterson \& A. R. D'Augelli (Eds.), Lesbian, gay, and bisexual identities in families: Psychological perspectives (pp. 270-291). New York, NY: Oxford University Press.

Medalie, J. H., \& Goldbourt, U. (1976). Angina pectoris among 10,000 men: Psychosocial and other risk factors. American Journal of Medicine, 60, 910-921. doi:10.1016/0002-9343(76)90921-9

Mischel, W., Shoda, Y., \& Peake, P. K. (1988). The nature of adolescent competencies predicted by preschool delay of gratification. Journal of Personality and Social Psychology, 54, 687-696. doi:10.1037/00223514.54.4.687

Morman, M. T., \& Floyd, K. (2002). A "changing culture of fatherhood": Effects on affectionate communication, closeness, and satisfaction in men's relationships with their fathers and their sons. Western Journal of Communication, 66, 395-411.

Morris, J. F., Balsam, K. F., \& Rothblum, E. D. (2002). Lesbian and bisexual mothers and nonmothers: Demographics and the coming-out process. Developmental Psychology, 16, 144-156.

Mroczek, D., \& Almeida, D. M. (2004). The effect of daily stress, personality, and age on daily negative affect. Journal of Personality, 72, 355-378. doi:10.1111/j.0022-3506.2004.00265.x

Mroczek, D. K., \& Kolarz, C. (1998). The effect of age on positive and negative affect: A developmental perspective on happiness. Journal of Personality and Social Psychology, 75, 1333-1349. doi:10.1037/00223514.75.5.1333

Nezlek, J. B. (2001). Multilevel random coefficient analyses of event- and interval-contingent data in social and personality psychology research. 
Personality and Social Psychology Bulletin, 27, 771-785. doi:10.1177/ 0146167201277001

Nord, C. W., Brimhall, D., \& West, U. (1997). Fathers' involvement in their children's schools (ED 409125). Washington, DC: U.S. Department of Education.

Paquette, D. (2004). Theorizing the father-child relationship: Mechanisms and developmental outcomes. Human Development, 47, 193-219. doi: $10.1159 / 000078723$

Parke, R. D. (1996). Fatherhood. Cambridge, MA: Harvard University Press.

Parke, R. D., \& Tinsley, B. J. (1987). Parent-infant interaction. In J. Osofsky (Ed.), Handbook of infancy (pp. 579-641). New York, NY: Wiley.

Parker, G., Tupling, H., \& Brown, L. B. (1979). A parental bonding instrument. British Journal of Medical Psychology, 52, 1-10.

Pearlin, L. I., Lieberman, M. A., Menaghan, E., \& Mullan, J. T. (1981). The stress process. Journal of Health and Social Behavior, 22, 337-356. doi: $10.2307 / 2136676$

Pearlin, L. I., \& Schooler, C. (1978). The structure of coping. Journal of Health and Social Behavior, 19, 2-21. doi:10.2307/2136319

Pleck, E. H., \& Pleck, J. H. (1997). Fatherhood ideals in the United States: Historical dimensions. In M. E. Lamb (Ed.), The role of the father in child development (3rd ed., pp. 33-48). New York, NY: Wiley.

Pleck, J. (1997). Paternal involvement: Levels, sources, and consequences. In Lamb, M. E. (Ed.), The role of the father in child development (3rd ed., pp. 66-103). Hoboken, NJ: Wiley.

Prenda, K. M., \& Lachman, M. E. (2001). Planning for the future: A life management strategy for increasing control and life satisfaction in adulthood. Psychology and Aging, 16, 206-216. doi:10.1037/08827974.16.2.206

Radin, N. (1982). Primary caregiving and role-sharing fathers of preschoolers. In M. E. Lamb (Ed.), Nontraditional families: Parenting and child development (pp. 173-204). Hillsdale, NJ: Erlbaum.

Raudenbush, S. W., \& Bryk, A. S. (2002). Hierarchical linear models: Applications and data analysis methods (2nd ed.). Thousand Oaks, CA: Sage.

Repetti, R. L., Taylor, S. E., \& Seeman, T. E. (2002). Risky families: Family social environments and the mental and physical health of offspring. Psychological Bulletin, 128, 330-366. doi:10.1037/00332909.128.2.330

Roberts, R., \& Bengtson, V. (1996). Affective ties to parents in early adulthood and self-esteem across 20 years. Social Psychology Quarterly, 59, 96-106. doi:10.2307/2787121

Rossi, A. S. (2001). Caring and doing for others: Social responsibility in the domains of family, work, and community. Chicago, IL: University of Chicago Press.

Rossi, A. S., \& Rossi, P. H. (1990). Of human bonding: Parent-child relations across the life course. New York, NY: de Gruyter.

Russek, L. G., \& Schwartz, G. E. (1996). Narrative descriptions of parental love and caring predict health status in midlife: A 35-year follow-up of the Harvard Mastery of Stress Study. Alternative Therapies in Health and Medicine, 2, 55-62.

Russek, L. G., \& Schwartz, G. E. (1997). Feelings of parental caring predict health status in midlife: A 35-year follow-up of the Harvard Mastery of Stress Study. Journal of Behavioral Medicine, 20, 1-13. doi:10.1023/A:1025525428213

Saracho, O. N., \& Spodek, B. (2008). Fathers: The "invisible" parents. Early Child Development and Care, 178, 821-836. doi:10.1080/03004430802352244

Seeman, T. E., \& Syme, L. S. (1987). Social networks and coronary artery disease: A comparison of the structure and function of social relations as predictors of disease. Psychosomatic Medicine, 49, 341-354.

Shaw, B. A., Krause, N., Chatters, L., Connell, C., \& Ingersoll-Dayton, B. (2003). Social structural influences on emotional support from parents early in life and adult health status. Behavioral Medicine, 29, 68-79. doi:10.1080/08964280309596059

Shaw, B. A., Krause, N., Chatters, L., Connell, C., \& Ingersoll-Dayton, B. (2004). Emotional support from parents early in life, aging, and health. Psychology and Aging, 19, 4-12. doi:10.1037/0882-7974.19.1.4

Shumaker, S. A., \& Czajkowski, S. M. (Eds.). (1994). Social support and cardiovascular disease. New York, NY: Plenum Press.

Siegal, M. (1987). Are sons and daughters treated more differently by fathers than by mothers? Developmental Review, 7, 183-209. doi: 10.1016/0273-2297(87)90012-8

Starrels, M. (1994). Gender differences in parent-child relations. Journal of Family Issues, 15, 148-165. doi:10.1177/019251394015001007

Staudinger, U. M., Fleeson, W., \& Baltes, P. B. (1999). Predictors of subjective physical health and global well-being: Similarities between the United States and Germany. Journal of Personality and Social Psychology, 76, 305-319. doi:10.1037/0022-3514.76.2.305

Suls, J., Green, P., \& Hillis, S. (1998). Emotional reactivity to everyday problems, affective inertia, and neuroticism. Personality and Social Psychology Bulletin, 24, 127-136. doi:10.1177/0146167298242002

Suls, J., \& Martin, R. (2005). The daily life of the garden variety neurotic: Problem exposure, hyperreactivity, mood spillover and maladaptive coping. Journal of Personality, 73, 1485-1510. doi:10.1111/j.14676494.2005.00356.x

Tamis-LeMonda, C. S., Shannon, J. D., Cabrera, N., \& Lamb, M. (2004). Fathers and mothers at play with their 2- and 3-year-olds: Contributions to language and cognitive development. Child Development, 75, 18061820. doi:10.1111/j.1467-8624.2004.00818.x

Taylor, S. E., Lerner, J., Sage, R., Lehman, B., \& Seeman, T. (2004). Early environment, emotions, responses to stress, and health. Journal of Personality, 72, 1365-1394. doi:10.1111/j.1467-6494.2004.00300.x

Tennen, H., Suls, J., \& Affleck, G. (1991). Personality and daily experience: The promise and the challenge. Journal of Personality, 59, 313-336.

Turner, H. A., \& Muller, P. A. (2004). Long-term effects of child corporal punishment on depressive symptoms in young adults. Journal of Family Issues, 25, 761-782. doi:10.1177/0192513X03258313

Umberson, D. (1992). Relationships between adult children and their parents: Psychological consequences for both generations. Journal of Marriage and the Family, 54, 664-674. doi:10.2307/353252

Watson, D., \& Pennebaker, J. W. (1989). Health complaints, stress, and distress: Exploring the central role of negative affectivity. Psychological Review, 96, 234-254. doi:10.1037/0033-295X.96.2.234

Wickrama, K. A. S., Lorenz, F. O., \& Conger, R. D. (1997). Parental support and adolescent health: A growth curve analysis. Journal of Health and Social Behavior, 38, 149-163. doi:10.2307/2955422

Yogman, M. W., Kindlon, D., \& Earls, F. (1995). Father involvement and cognitive/behavioral outcomes of preterm infants. Journal of the American Academy of Child and Adolescent Psychiatry, 34, 58-66. doi: 10.1097/00004583-199501000-00015

Received September 28, 2009 Revision received September 28, 2009 Accepted April 12, 2010 